\title{
Clinical and Radiological Outcomes of a Prospective Cohort of Patients Treated after a Vertebral Traumatic Fracture
}

\section{Javier Pizones ${ }^{\star}$, Lorenzo Zúñiga, Felisa Sánchez-Mariscal and Enrique Izquierdo}

Department of Orthopaedic Surgery, Spine Unit, Hospital Universitario de Getafe, Madrid, Spain

*Corresponding author: Javier Pizones, Department of Orthopaedic Surgery, Hospital Universitario de Getafe, Carretera de Toledo Km. 12.5 28905, Madrid, Spain, Tel: 0034616644876; Fax: 0034913591351; E-mail: javier.pizones@gmail.com

Rec Date: May 28, 2014; Acc Date: Aug 28, 2014; Pub Date: Aug 30, 2014

Copyright: (C) 2014 Pizones J, et al. This is an open-access article distributed under the terms of the Creative Commons Attribution License, which permits unrestricted use, distribution, and reproduction in any medium, provided the original author and source are credited

\begin{abstract}
Study background: There is still controversy on the effectiveness of conservative treatment and the need for surgical intervention in thoracolumbar burst fractures. The aim of the study was to prospectively evaluate the results of a cohort of patients with acute thoracolumbar fractures comparing surgical and conservative treatment.

Methods: Forty-five patients were included. Treatment was decided upon fracture stability and clinical involvement. Two groups were made: surgical (S-group) and conservative (Cgroup). Radiological variables at initial presentation, 1-month, 6-months and at 2-years follow-up were analyzed. Local and regional kyphosis, SF-36 and Oswestry Disability Index (ODI) results, and complications were compared.

Results: $54.8 \%$ were type A2-A3 fractures, and 45.2\% were type B1-B2 fractures. L1 was the most often affected level, mean age was $40.3 \pm 13.2$ years, and both groups were homogeneous except for type of fracture according to the AO classification. Group $\mathrm{C}$ had mostly A types, group $\mathrm{S}$ had mostly B types. Statistically significant differences $(p<0.05)$ were found for local initial kyphosis $\left(C: 12.4^{\circ} \pm 3.6\right.$ vs $S$ : $\left.17.5^{\circ} \pm 6\right)$; local and regional kyphosis at 1 and 6 months; and final local kyphosis (C: $14.8^{\circ} \pm 6.2$ vs $S: 7.3^{\circ} \pm 4.6$ ). At the end of follow-up, patients undergoing conservative management showed $a+2.6^{\circ} \pm 4.1$ increase in local kyphosis, whereas those with surgical treatment showed a $-10.3^{\circ} \pm 5.6$ improvement $(p=0.000)$. At two years there was a non-significant trend favoring conservative treatment in all SF-36 domains except emotional role. Patients who underwent conservative treatment showed less final disability on the ODI(C: $13.5 \%$ vs S: $29.8 \% \mathrm{p}=0.006)$. Two conservatively treated patients had a $>20^{\circ}$ increase in kyphosis at final follow-up and one required surgery. In the S group the reoperation rate was $22 \%$.
\end{abstract}

Conclusion: Fractures with doubtful posterior ligamentous complex instability are better treated by conservative means. Kyphosis would not be restored, but clinical outcomes will result better than if treated surgically, with less complication.

Keywords: Thoracolumbar fractures; Conservative treatment; Surgical treatment

\section{Introduction}

Over the past years, several classification systems have been developed in order to help clinicians not only to classify vertebral fractures, but also to guide treatment. Nevertheless, some fractures that lay in a "grey diagnostic zone", difficult to establish if they are unstable or not, can be treated either by conservative or surgical means. Even the management of some unstable traumatic thoracolumbar fractures remains unclear, tending in recent decades towards more operative treatment [1]

Doubts still arise in the decision making of common burst fractures with mild collapse, mild comminution, little canal encroachment, and no neurological injury. In some cases, stability is difficult to diagnose even using both CT and MR imaging tools. Reports still debate whether the results are better if treated surgically or conservatively [1]. Surgery seems to improve residual kyphosis but not pain and function, and it comprises more complications and costs $[1,2]$
We conducted a prospective study to analyze the 2-year clinical and radiological results of a cohort of consecutive patients treated after a vertebral traumatic thoracolumbar fracture. A comparison was performed between those patients treated conservatively with those who underwent surgery.

\section{Material and Methods}

A prospective non-randomized study was conducted with a cohort of patients treated during a two-year period for an acute traumatic thoracolumbar fracture in a single institution. Informed consent was gathered and the study followed the Helsinki principles. Exclusion criteria were pathological fractures: secondary to infection, osteoporosis or tumor.

The demographic analyzed variables were: age, gender, $\mathrm{AO}$ fracture type [3], fracture localization, received treatment. Each fracture was studied with plain X-rays, a CT scan and an MRI with fat-saturation protocol [4] before deciding treatment. Standing AP and lateral X-rays were performed during follow-up at one month, three months, six months, one year and two years. Local and regional kyphosis was measured at each time point. Local kyphosis was measured as the angle between the inferior endplate and the superior endplate of the 
Page 2 of 4

affected vertebra. Regional kyphosis as the angle between the inferior endplate of one level below the affected vertebra and the superior endplate of one level above. At final follow-up SF-36 test and Oswestry Disability Index (ODI) were recorded, as well as complications.

The indication for treatment was not randomized, and depended on fracture morphological stability and patient's comorbidities. X-rays, CT scan and T1-w MRI sequences determined the osseous involvement of the fracture. Fat-saturation and STIR T2-w sagittal and axial sequences were used to asses disc and ligaments, specially posterior ligamentous complex (PLC) damage. The integrity of the supraspinous ligament dictated soft tissue instability as established in the literature [5], which in conjunction with the osseous injury defined fracture classification and treatment. As said, the Magerl's AOclassification [3] was adopted for the study. Surgery was indicated when radiological assessment showed mechanical instability and/or neurological deficits were present. Neurological deficits were graded according to the ASIA scale. Mechanical instability could be due to poor bone quality, osseous involvement, or posterior band instability (PLC rupture). The typical patterns were AO type A2 conminuted fractures, A3 unstable fractures, and B1 fractures. Conservative treatment when these signs were not encountered: when the osseous damage was limited, when bone quality initially precluded further bone compression and when the PLC showed integrity and mechanical stability. These where usually type A1, A2, A3 (incomplete burst fractures) with stable PLC, and B2 Chance fractures. Patient's comorbidities were also taken into account for decision making.

Surgical treatment consisted mostly on posterior open approaches with short segment screw-rod fixation and fusion. When comminution exceeded $50 \%$ of the vertebral body, or canal encroachment was severe and/or neurology was affected, an anterior approach was performed and a mesh cage filled with autogenous bone graft was placed. Conservative treatment consisted on a well molded body jacket (total body contact TLSO) left a mean of 12 weeks, followed by intensive rehabilitation program for 4 weeks.

Statistical analysis was performed using SPSS software (version 11.5, SAS Institute Inc, Cary, NC, USA). A comparative analysis was performed between those patients treated conservatively (C group) and those treated surgically (S group). Qualitative variables were compared using the chi-square test and quantitative variables with the Mann Whitney $U$ test. The significance level was set at $5 \%(p<0.05)$.

\section{Results}

Forty-five patients were included in the study, three of them were lost to follow-up, which gave us a response rate of $93.3 \%$. Total sample description was as follows: 23 were males, 19 females; mean age $40.3 \pm$ 13.2 years; fracture localization was: $16.7 \%$ in the thoracic area, $76.2 \%$ thoracolumbar (T10-L2), and 7.1\% lumbar; L1 was the most often affected level (35.7\%). According to the AO classification: $54.8 \%$ were type A (A2 split fractures and A3 burst fractures), and 45.2\% type B (B1 ligamentous Chance fractures and B2 Chance fractures). Surgical treatment was performed in $53 \%$ of the patients (S Group), the majority by posterior-only instrumented fusion. Only three patients (including the only two patients with incomplete neurology) required an additional anterior approach and support. The other $47 \%$ of patients were managed conservatively (C Group). The two patients that suffered neurological deficits had type A3 complete burst fractures, and their impairment consisted on transient unilateral L1 root radiculopathy (ASIA D). Both groups were homogeneous in all demographic variables except for fracture type. In the surgical group, $26.1 \%$ type A, $73.9 \%$ type B fractures were treated. In the conservative group $89.5 \%$ were type A and $10.6 \%$ were type B fractures (specifically type B2).

When comparing group results, statistically significant differences $(\mathrm{P}<0.05)$ were found for local initial kyphosis, 1-month local and regional kyphosis, 6-months local and regional kyphosis, and final local kyphosis. The summary of these data is shown in (Table 1).

\begin{tabular}{|c|c|c|c|}
\hline & $\begin{array}{l}\text { Conservative } \\
\text { Group }\end{array}$ & $\begin{array}{l}\text { Surgical } \\
\text { Group }\end{array}$ & $\begin{array}{l}\text { P (Mann- } \\
\text { Whitney) }\end{array}$ \\
\hline Age & $43.9 \pm 13.5$ & $37.4 \pm 12.5$ & 0.17 \\
\hline Initial Local Kyphosis* & $12.4 \pm 3.6$ & $17.5 \pm 6$ & 0.003 \\
\hline Initial Regional Kyphosis & $12.3 \pm 7$ & $16 \pm 8.2$ & 0.18 \\
\hline 1-month Local Kyphosis* & $12.8 \pm 7.2$ & $6.4 \pm 4.8$ & 0.000 \\
\hline 1-month Regional Kyphosis ${ }^{*}$ & $12.8 \pm 7.9$ & $7.1 \pm 5.2$ & 0.000 \\
\hline $\begin{array}{l}\text { 1-month Local Kyphosis } \\
\text { Difference }^{*}\end{array}$ & $0.56 \pm 5$ & $-10.7 \pm 6.3$ & 0.000 \\
\hline $\begin{array}{l}\text { 1-month Regional Kyphosis } \\
\text { Difference }^{*}\end{array}$ & $1.3 \pm 5.1$ & $-9.2 \pm 7$ & 0.000 \\
\hline 6-months Local Kyphosis* & $14.1 \pm 7$ & $7.3 \pm 5$ & 0.000 \\
\hline 6-months Regional Kyphosis ${ }^{*}$ & $14.9 \pm 7.9$ & $9.4 \pm 6.2$ & 0.02 \\
\hline 2 yrs. Local Kyphosis* & $14.8 \pm 6.2$ & $7.3 \pm 4.6$ & 0.000 \\
\hline 2 yrs. Regional Kyphosis & $14.2 \pm 8.3$ & $10.6 \pm 7.1$ & 0.2 \\
\hline $\begin{array}{l}\text { Final Local Kyphosis } \\
\text { Difference* }^{*}\end{array}$ & $2.6 \pm 4.1$ & $-10.3 \pm 5.6$ & 0.000 \\
\hline $\begin{array}{l}\text { Final Regional Kyphosis } \\
\text { Difference }\end{array}$ & $1.7 \pm 5.8$ & $-6.1 \pm 8$ & 0.004 \\
\hline
\end{tabular}

Table 1: Comparative results between surgical y conservative treated patients

The important fact is that at the end of the two year follow-up, patients undergoing conservative management showed a $+2.6^{\circ} \pm 4$ increase in local kyphosis and $1.7^{\circ} \pm 5.8$ in regional kyphosis when compared with initial kyphosis, whereas those with surgical treatment showed an improvement/correction of $-10.3^{\circ} \pm 5.6$ in local kyphosis and $-6.1^{\circ} \pm 8$ in regional kyphosis $(\mathrm{P}=0.00)$.

At two years follow-up there was a non-significant trend favoring conservative treatment in all SF-36 domains except emotional role (Table 2).

Patients who underwent conservative treatment showed less final disability on the ODI scores (C: $13.5 \% \pm 14.6$ vs S: $29.8 \% \pm 14.6$ $\mathrm{p}=0.006$ ).

Two conservatively treated patients (type A3 stable fractures) had a $>20^{\circ}$ increase in kyphosis at final follow-up and one required surgery. In the surgical group, there was one reoperation involving corrective transpedicular osteotomy, one revision surgery to extend fusion because of distal screw pull-out, and 3 cases of instrumentation removal: 2 due to pain, and one who suffered a deep infection. The reoperation rate in this surgical group was $22 \%$. 


\begin{tabular}{|l|l|l|l|l|l|}
\hline & \multicolumn{2}{|l|}{ Conservative } & \multicolumn{2}{l|}{ Surgical } & $\begin{array}{l}\text { P (Mann- } \\
\text { Whitney) }\end{array}$ \\
\hline SF-36 & Mean & SD & Mean & SD & \\
\hline $\begin{array}{l}\text { Phys. } \\
\text { function }\end{array}$ & 78.3 & 20.3 & 62.4 & 19.6 & 0.055 \\
\hline Phys. role & 72.5 & 36.2 & 46.5 & 43.4 & 0.18 \\
\hline Bodily pain & 60.3 & 30.9 & 48.0 & 21.0 & 0.18 \\
\hline $\begin{array}{l}\text { General } \\
\text { health }\end{array}$ & 63.2 & 23.5 & 54.1 & 15.7 & 0.35 \\
\hline Vitality & 59.5 & 20.20 & 47.5 & 21.3 & 0.12 \\
\hline $\begin{array}{l}\text { Social } \\
\text { function }\end{array}$ & 72.4 & 25.6 & 70.8 & 25.7 & 0.92 \\
\hline $\begin{array}{l}\text { Emotional } \\
\text { role }\end{array}$ & 43.3 & 41.7 & 58.3 & 51.5 & 0.61 \\
\hline $\begin{array}{l}\text { Mental } \\
\text { health }\end{array}$ & 68.4 & 21.8 & 58.3 & 21.4 & 0.30 \\
\hline
\end{tabular}

Table 2: Comparative results of the SF-36 health questionnaire

\section{Discussion}

Vertebral fracture stability is still difficult to diagnose. Plain X-rays and CT images may sometimes appear similar between a pure burst fracture and an unstable burst fracture. Thus different signs should be looked for, especially discoligamentus injury and posterior ligamentous complex disruptions [6]. 25\% of burst fractures can be misdiagnosed as compression fractures if CT and MRI scans are not performed and carefully evaluated [7]. As the designers of the AO classification stated, some type B injuries are missed and classified as type A when only standard radiographs are performed [3], and Leferink et al. found that $30 \%$ of type B fractures were unrecognised using traditional examination tools (X-rays and CT scan) [8]. Special attention should be taken in the evaluation of posterior ligamentous complex integrity. Fat saturation MRI protocols have shown to provide important information of soft tissue structures [4]. Although recently, both the Magerl [3] (AO-classification) and the TLICS system [9] have been revised [10], improved, and even mixed in a new classification [11], there is still no clear stability definition for the "grey zone" fractures: fractures with moderate osseous involvement and doubtful ligamentous damage. This leads to difficulties in treatment decision making.

There is a considerable controversy on the effectiveness of conservative treatment and the need for surgical intervention in vertebral burst fractures. Need for additional stability, prevention of neurological deterioration, attainment of canal clearance, prevention of kyphosis and early relief of pain are the commonly quoted reasons for surgical intervention [7]. Numerous authors have reported excellent results after non-operative management of burst fractures without reduction. On the other hand, proponents of surgery believe that decompression, fracture reduction and stabilisation are essential for stabilising neurology and reducing pain.

In patients treated conservatively with orthosis, the range of kyphosis progression is from $1-6^{\circ}$, mostly occurring in the early posttraumatic months and then stabilizing [12-15]. Usually, posterior short segment instrumentation provides better postoperative kyphosis

correction, with some recurrence during follow-up [15-17]. However, some of these studies show that there is no direct relationship between kyphosis and back-pain or functional impairment either with conservative or surgical treatment [12-14,18]

Studies that have compared operative and nonoperative management of burst fractures conclude that, even though short and long term radiological results may be slightly better in the surgical group, there is no significant difference in treatment outcome in terms of back pain and functionality between the groups [17,19-21].

Our study include from type A2 to type B2 fractures, corresponding with patterns that can be either conservative or surgically managed depending on the specific features of the case. No randomization was introduced, as treatment depended on fracture stability or patient's specific comorbidities. We demonstrate that surgical management allowed an adequate reposition of sagittal harmony, decreasing in a mean of $10^{\circ}$ the local kyphosis. On the other hand, conservative treatment led to a $2.6^{\circ}$ increase in local kyphosis, most probably due to disc and osseous fragment settling. In spite of the sagittal profile results, patients who received conservative treatment showed half the scores of final disability than surgical patients, and a better perception of function, physical role, bodily pain, general health and vitality.

From our perspective, when the osseous component of the fracture show mild to moderate involvement, PLC damage should be carefully taken into consideration for decision making. If ligamentous rupture is evident, instability can be present and the fracture should be surgically treated, with correction of the kyphosis, instrumented fusion and anterior support if needed, even knowing that at two years followup disability can be an issue. However, if the PLC (and especially de supraspinous ligament) is intact we recommend a conservative treatment, even with interspinous ligament edema, increased spinous processes distance and capsular distraction. This decision could slightly increase local kyphosis, but in the long run, the patient is going to avoid a potential surgical complications and reach a better final quality of life, in terms of back pain and functionality.

The study has several limitations. Comparison between groups is homogeneous except for fracture type. Although the included fractures range from A2 to B2, and all could be treated with surgical means, there are more stable pattern fractures in the conservative group than in the surgical one. Randomization was not performed due to this same fact, as we thought that patients should be ethically treated with the best treatment option available. Sample size is small; however statistics do show important significance with these Figures 1 and 2. Results should be carefully interpreted until big prospective clinical trials are conducted.

\section{Conclusion}

Both the osseous involvement of the fracture and the injury of the disco-ligamentous structures are important in decision making. Whenever a compression or burst fracture is accompanied by a stable posterior ligamentous complex or there are doubts that the PLC is injured, it is better to treat the patient by conservative means. Kyphosis would perhaps not be restored, but clinical outcomes are going to be better than if treated surgically with less incidence of complications. Fractures with high body involvement and unstable PLC need surgical stabilization, this act restores kyphosis better than conservative treatment, but leads to possible complications and less satisfactory clinical results. 


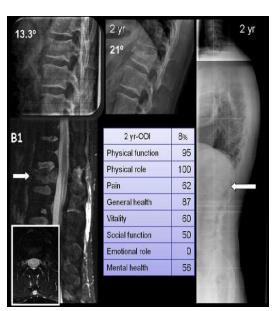

Figure 1: Conservative case of an L1 traumatic fracture in a 32 yearold male, showing $13.3^{\circ}$ of local kyphosis. MRI showing an incomplete burst fracture with indetermined PLC (AO type A3). After 2 years follow-up of conservative treatment, local kyphosis was $21^{\circ}$ ( $7^{\circ}$ of loss) but ODI showed an $8 \%$ disability

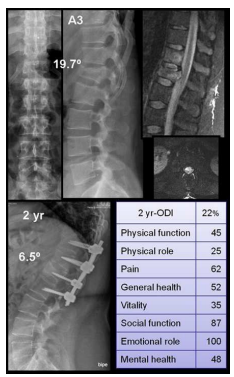

Figure 2: Surgical case of an L1 traumatic fracture in a 33 year-old male, showing $19.7^{\circ}$ of local kyphosis. MRI showing a complete burst fracture with PLC stability (AO type A3). After 2 years follow-up of a four level posterior fusion, local kyphosis was $6.5^{\circ}$ ( $13^{\circ}$ of correction) but ODI showed a $22 \%$ disability.

\section{References}

1. Van der Roer N, de Lange ESM, Bakker FC, de Vet HCW, van Tukler MW (2005) Management of traumatic thoracolumbar fractures: a systematic review of the literature. Eur Spine J 14: 527-534.

2. Gnanenthiran SR, Adie S, Harris IA (2012) Nonoperative versus operative treament forthoracolumbar burst fractures without neurologic deficit. Clin Orthop Relat Res 470: 567-577.

3. Magerl F, Aebi M, Gertzbein SD, Harms J, Nazarian S (1994) A comprehensive classification of thoracic and lumbar injuries. Eur Spine J 3: 184-201.

4. Lee JY, Vaccaro A, Schweitzer KM (2007) Assessment of injury to the thoracolumbar posterior ligamentous complex in the setting of normalappearing plain radiograph. Spine J 7: 422-427.

5. Pizones J, Zúliga L, Sánchez-Mariscal F, Alvarez P, Gómez-Rice A, et al. (2012) MRI study of post-traumatic incompetence of posterior ligamentous complex: importance of the supraspinous ligament. Prospective study of 74 traumatic fractures. Eur Spine J 21: 2222-2231.

6. Oner FC, van Gils APG, Faber JAJ, Dhert JA, Verbout AJ (2002) Some complications of common treatment schemes of thoracolumbar spine fractures can be predicted with magnetic resonance imaging. Prospective study of 53 patients with 71 fractures. Spine 27: 629-636.

7. Rajasekaran S (2010) Thoracolumbar burst fractures without neurological deficit: the role for conservative treatment. Eur Spine J 19 Suppl 1: S40-47.

8. Leferink VJ, Veldhuis EF, Zimmerman KW, ten Vergert EM, ten Duis HJ (2002) Classificational problems in ligamentary distraction type vertebral fractures: $30 \%$ of all B-type fractures are initially unrecognised. Eur Spine J 11: 246-250.

9. Vaccaro AR, Lehman RA Jr, Hurlbert RJ, Anderson PA, Harris M, et al. (2005) A new classification of thoracolumbar injuries: the importance of injury morphology, the integrity of the posterior ligamentous complex, and neurologic status. Spine (Phila Pa 1976) 30: 2325-2333.

10. Reinhold M, Audigé L, Schnake KJ, Bellabarba C, Dai LY, et al. (2013) $\mathrm{AO}$ spine injury classification system: a revision proposal for the thoracic and lumbar spine. Eur Spine J 22: 2184-2201.

11. Vaccaro AR, Oner C, Kepler CK, Dvorak M, Schnake K, et al. (2013) AOSpine Spinal Cord Injury \& Trauma Knowledge. Forum AOSpine thoracolumbar spine injury classification system: fracture description, neurological status, and key modifiers. Spine (Phila Pa 1976) 38: 2028-2037.

12. Mumford J, Weinstein JN, Spratt KF, Goel VK (1993) Thoracolumbar burst fractures. The clinical efficacy and outcome of nonoperative management. Spine (Phila Pa 1976) 18: 955-970.

13. Chow GH, Nelson BJ, Gebhard JS, Brugman JL, Brown CW (1996) Functional outcome of thoracolumbar burst fractures managed with hyperextension casting or bracing and early mobilization. Spine (Phila Pa 1976) 21:2170-2175.

14. Tropiano P, Huang RC, Louis CA, Poitout DG, Louis RP (2003) Functional and radiographic outcome of thoracolumbar and lumbar burst fractures managed by closed orthopaedic reduction and casting. Spine (Phila Pa 1976) 28: 2459-2465.

15. Shen WJ, Liu TJ, Shen YS (2001) Nonoperative treatment versus posterior fixation for thoracolumbar junction burst fractures without neurologic deficit. Spine (Phila Pa 1976) 26: 1338-1345.

16. White AA, Panjabi MM (1978) Clinical biomechanics of the spine. Philadelphia

17. Resch H, Rabl M, Klampfer H, Ritter E, Povacz P (2000) [Surgical vs. conservative treatment of fractures of the thoracolumbar transition]. Unfallchirurg 103: 281-288.

18. Kramer DL, Rodgers WB, Mansfield FL (1995) Transpedicular instrumentation and short-segment fusion of thoracolumbar fractures: a prospective study using a single instrumentation system. J Orthop Trauma 9: 499-506.

19. Knight RQ, Stornelli DP, Chan DP, Devanny JR, Jackson KV (1993) Comparison of operative versus nonoperative treatment of lumbar burst fractures. Clin Orthop Relat Res 112-121.

20. Seybold EA, Sweeney CA, Fredrickson BE, Warhold LG, Bernini PM (1999) Functional outcome of low lumbar burst fractures. A multicenter review of operative and nonoperative treatment of L3-L5. Spine (Phila Pa 1976) 24: 2154-2161.

21. Wood KB, Khanna G, Mehbod A, Garvey T, Jhanjee R, Sechriest V (2003) Operative compared with nonoperative treatment of a thoracolumbar burst fracture without neurological deficit. A prospective, randomized study. J Bone Joint Surg Am 85-A: 773-781. 